\title{
Rawls e um intuicionismo mitigado: intérprete do Liberalismo de Mill
}

\author{
Everton Miguel Puhl Maciel ${ }^{1}$
}

1 Doutor em Filosofia (PUC-RS), professor de Filosofia da Universidade Federal do Amapá. E-mail: jornalistamaciel@gmail.com

RESUMO: nosso objetivo neste trabalho é, em primeiro lugar, apresentar o modelo de liberalismo proposto por John Stuart Mill como relevante para o construtivismo da teoria política de John Rawls. Para tal, vamos mostrar que o contratualista americano em alguma medida subscreve o liberalismo do utilitarista inglês. Vamos aproximar ambos os autores no tocante ao método intuicionista e verificar se ainda há alguma vantagem no consequencialismo de Mill. Para Rawls, um procedimento intuicionista é ligado a um conjunto de princípios que não pode ser reduzido. Mill se encaixa na definição, portanto, na medida em que advoga um tipo de hedonismo, característica que o americano descarta, por poder ser listada como teoria moral abrangente, em virtude da redução apontada por Rawls. Mesmo assim, precisamos verificar até que medida é possível considerar o método intuicionista de Mill como tendo influenciado o liberalismo de Rawls. Assim, levaremos em conta que ele autorizou, pelo menos parcialmente, um método intuicionista e mostraremos que isso se deu por influência da filosofia política de Mill. Fica assim admitido que o apelo à intuição está na base da teoria da justiça, mas tudo somado pode ficar perfeitamente claro onde reside o "equilíbrio lógico", nas palavras do próprio Rawls. Mesmo com o desacordo final, é possível notar a influência do projeto liberal do londrino em torno da teoria política que resultou na Teoria da Justiça. Restará ainda tentar saber se realmente é possível se afastar de um consequencialismo e se há alguma vantagem teórica em se manter filiado a uma teoria política e ética como a de Mill do ponto de vista jurídico institucional. Isso porque o consequencialismo com um viés estritamente constitucional, como aquele sugerido por Rawls, não parece ser capaz de solucionar um problema jurídico externo ao hermético sistema teórico proposto nas teorias da justiça contemporâneas.

Palavras-chave: liberalismo, utilitarismo, contratualismo, intuicionismo.

ABSTRACT: this paper has the subject first show us a liberalism model claim by John Stuart Mill as important to John Rawls political constructivism. We will present some way the American contractualist agree with English utilitarianist`s liberalism. We must do a approach both authors around methods intuitionist and we search if there is any advantage on Mill's consequentialism. For Rawls, a procedure intuitionist is connected to a principle set then can not be reduced. Mill is in intuitionist definition, because he uses a kind hedonism, features which Rawls does not agree, he see as comprehensive moral theory. Anyway, we need kwon if is possible the Mill's utilitarianism has some influence on Rawls liberalism. We must account Rawls used a kind intuitionist method, by Mill's influence. Another hand it is admitted an intuition appeal in justice theory basis, but all Rawls's argument can leave logical clear. Even final disagree conclusion, this is possible seen how Londoner liberal project influences A Theory of Justice. By conclusion, we need to try kwon if is possible it ignores the consequentialism and in there is any theorical advantage keep an ethical and political theory like Mill did, on concern institutional juridical aspect. The kind of consequentialism apply just on constitutional sense, how Ralws did it, does not be able to solve a juridical problem off theoretical system so closed, exposed on contemporary theories of justice.

Keywords: liberalism, utilitarianism, contractualism, intuitionism. 


\section{Considerações iniciais}

Nosso trabalho parte do pressuposto de que as virtudes e defeitos de teorias políticas devem ser avaliadas levando em conta os sistemas teóricos inteiros frente às experiências, e mostraremos que essa expectativa dos liberais em destaque. John Stuart Mill foi o mais relevante filósofo liberal a levar um empreendimento deste tipo a cabo no século XIX. Nesse contexto, a objetividade dos valores contidos nos princípios da liberdade e igualdade ampara-se no fato da impossibilidade de uma dicotomia absoluta entre fatos e valores e não na necessidade de equivalência ${ }^{1}$.

O caminho percorrido por Mill se assenta sobre um critério político, diante de um permanente diálogo com os principais problemas da ética. Dizemos isso levando em conta uma justificação de seus princípios através de valores historicamente acordados entre os cidadãos de uma determinada comunidade moral. Pretendemos mostrar a influência desses valores no liberalismo contemporâneo através do liberalismo político de John Rawls. Nosso objetivo indireto é argumentar que Mill estava autorizado a tratar do conceito político de liberdade, sem que haja uma falácia naturalista, ligada à "prova" do princípio da utilidade, o

${ }^{1}$ A chamada "falácia naturalista" de Moore, que colocou em xeque utilitaristas como Bentham e Mill, só foi suficientemente desmantelada por Putnam. Uma melhor compreensão da filosofia da linguagem para tratar dos padrões de investigações científicas como sendo capazes de reconhecer valores epistêmicos básicos como "coerência" e "simplicidade", não como propriedades imprecisas de teorias, mas apenas, como atitudes individuais para com as teorias. Tais valores básicos são, por certo, subjetivos, porque a "aceitabilidade não pode ser mais objetiva do que os parâmetros sobre aqueles dos quais ela depende". No entanto, Putnam defende que ao menos alguns valores devem, sim, ser objetivos, no que se refere ao conteúdo do fato. Não havendo uma concepção de racionalidade que objetivamente "devamos" obrigatoriamente ter, então a noção de fato é vazia. "Sem os valores cognitivos de coerência, simplicidade, e eficácia instrumental, nós não temos mundo ou 'fatos', nem mesmo fatos sobre o que é relativo ao quê", assevera Putnam. Ele apoia a objetividade de valores elementares em fatos que ultrapassam a mera discricionariedade da realidade. Existe, assim, uma dependência de valores que se referem sempre a determinados fatos quando descrevemos uma pessoa como "imprudente, pensa apenas em si mesmo, faria tudo por dinheiro", apenas nos mantendo fiéis aos exemplos de Putnam. Nessa esteira, poderíamos criticar o relato de alguém que não emprega adequadamente os termos "livre", "igual”, "imparcial” para se referir a fatos políticos quando esse emprego é exigido. Para Putnam, a objetividade dessas descrições - que já são valorativas! - é guiada por uma ideia de bem, já presente inclusive nas ciências exatas (coerência, simplicidade etc.): "penso que o restante da nossa ideia de bem pode ser lida dos nossos padrões de aceitabilidade racional, ainda em outras áreas do conhecimento". Levando em conta que existem valores objetivos no campo cognitivo, como o de "justificação", Putnam vai contra o subjetivismo moral pela ideia de que existe uma diferença entre o subjetivismo e uma projeção usada para descrever determinado axioma moral. Se tomarmos como exemplo "a liberdade é moralmente boa", estamos nos referindo a uma projeção da ideia de liberdade e não precisamos explicar todos os sentidos aos quais isso se refere em uma teoria liberal para sermos compreendidos. "Se a irredutibilidade da ética à física mostra que valores são projeções, então cores também são projeções. Tanto quanto os números naturais são. Tanto quanto, para esse assunto, é 'o mundo físico'. Mas ser uma projeção nesse sentido não é a mesma coisa que ser subjetivo". Mesmo que não exista uma equivalência entre a falácia naturalista de Moore e o problema da dicotomia fato-valor de Putnam, fica suficientemente claro a impossibilidade de demonstrar premissas morais em torno do "bom", contudo isso não implica, necessariamente, que enunciados éticos não são racionalmente justificáveis. Nesses termos, o mundo dos fatos e valores se relaciona de tal forma que uma sentença do tipo "ele é honesto" depende dos valores racionalmente acordados, mesmo quando há apenas pretensões descritivas.

"[...] acceptability, cannot be more objective than the parameters upon it depends" (1998, p.135).

"Without the cognitive values of coherence, simplicity, and instrumental efficacy we have no world and 'facts', not even facts about what is so relative to what" (1998, p.136).

““[...] inconsiderate', 'thinks only about himself', 'would do anything for money'” (1998, p.139).

“[...] I think that the resto $f$ our idea of the good can be read off from our standards of rational acceptability in yet other areas of knowledge" (1998, p.137).

"If the irreducibility of ethics to physics shows that values are projections, then colors are also projections. So are the natural numbers. So, for that matter, is 'the physical world'. But being a projection in this sense is not the same thing as being subjective" (1998, p.147). 
preceito moral mais abrangente da sua teoria. Mill, portanto, tratou conceitos da política com substancialmente valiosos, assim como o fez com elementos da ética, quando seguiu na esteira benthamista de aproximar o certo e errado dos elementos de prazer e dor, respectivamente.

\section{O liberalismo em Mill e Rawls: limites do intuicionismo e do papel das ins- tituições}

Uma das mais influentes correntes políticas contemporâneas deve seu mérito, em parte, ao bem sucedido afastamento do utilitarismo e do intuicionismo. O próprio John Rawls anuncia ser precisamente essa sua intenção no prefácio (2002, p. XXIs) de Uma Teoria da Justiça. A obra também tem como mérito central a elaboração teórica e sistemática de princípios de justiça que atendem anseios políticos contemporâneos, por meio de um procedimento filosoficamente engenhoso envolvendo posição original, equilíbrio reflexivo e um método baseado no construtivismo político. O resultado estabelecido por Rawls leva em conta a estrutura básica de sociedades liberais e razoáveis e a emblemática concepção de justiça social, baseada na cooperação contratualista. Fatos políticos estabelecidos por meio desses procedimentos são valiosos para deliberações públicas, uma plataforma liberal que une os dois autores. Levando isso em consideração, podemos dizer que o liberalismo político, portanto, é uma característica também social - e não puramente procedimental - da justificação de princípios que conjugam fatos e valores dentro do mesmo corpo teórico. Contudo, como podemos fazer notar, não se trata de uma posição meramente procedimental, pois já sugestiona como deve ser o ambiente social para o qual a teoria está sendo construída.

Por certo, nosso objetivo neste trabalho não é mapear a teoria de Rawls no tocante aos seus pontos centrais, mas verificar até que medida é possível considerar o utilitarismo de Mill como tendo influenciado o liberalismo de Rawls. Para isso, vamos comparar o trabalho de Rawls e Mill no tocante ao seu método. Ainda, vamos tentar descobrir se realmente é possível se afastar de um consequencialismo e se há alguma vantagem teórica em se manter filiado a uma teoria política e ética consequencialista, como o utilitarismo declaradamente o é, sendo esse o ponto de encontro entre as muitas formas de utilitarismo. Observamos isso porque o hedonismo, característica mais latente das muitas formas de utilitarismo, representa justamente o ponto de afastamento entre teorias referentes à utilidade.

Em primeiro lugar, cabe salientar que a interpretação oferecida por Rawls sobre o utilitarismo clássico não é em nada tão caricata quanto a de Moore que acusou os utilitaristas clássicos de cometerem uma "falácia naturalista"; contudo, é preciso chamar atenção para seus conceitos-chave, pois, coerentemente, vão de encontro com os problemas centrais do autor. Rawls concentra-se predominantemente no utilitarismo de Sidgwick, em razão de ali estar parte do seu tema central, ligado ao âmbito institucional e à esfera da justiça ${ }^{2}$. A partir disso, Rawls busca uma explicação para seus juízos morais ponderados: “juízos nos quais

\footnotetext{
2 Não nos cabe aqui analisar o inegável mérito do utilitarismo de Sidgwick para a ética do final do vitorianismo, enquanto comparação equilibrada de métodos empregados pelos clássicos; é preciso dizer, contudo, que entre as influências importantes do eco provocado pela sua obra encontra-se a teoria da justiça de Rawls. A sociedade ordenada de forma correta e, portanto, justa, tem instituições planejadas de maneira a aumentar o saldo líquido de satisfação daqueles que a compõe. Sidgwick, ainda, ressaltou o elemento institucional, como ponto central para aprofundar o debate entre desejos individuais e aquilo que interessa à sociedade realmente maximizar: o saldo de satisfação geral. Ele dialogou com o senso de justiça intuitivo, tendo foco na justiça distributiva e reconhecendo os princípios da liberdade e igualdade de Mill como elementos indispensáveis do bem-estar. Contudo, isso não deve se limitar aos mecanismos institucionais compensatórios, por exemplo, na maximização da liberdade: "deve ser evidente que se compensação na forma de bens pode ser dada com justiça por uma invasão na Liberdade, a realização da Liberdade não pode ser o fim último da Justiça distributiva". É preciso mais do que a mera realização da liberdade para justificar
} 
as nossas qualidades morais têm o mais alto grau de probabilidade de se mostrarem sem distorção" (2002, p.51). O que nos interessa nesse tocante é a demonstração segundo a qual uma teoria ética precisa para ser aceita, segundo nosso entendimento, muito próxima da "prova" que Mill oferece na sua obra Utilitarism. Rawls pretendia que sua teoria da justiça ficasse passível das mesmas regras de método de outras teorias:

é impossível desenvolver uma teoria substantiva da justiça fundada unicamente em verdades lógicas e definições. A análise de conceitos morais e dos seus a priori, como quer que sejam entendidos tradicionalmente, é uma base frágil demais. A filosofia da ética deve ter a liberdade de usar hipóteses contingentes e fatos genéricos como lhe aprouver (2002, p.54).

Tendo o problema esse ângulo apresentado por Rawls, o projeto de Mill na ética é aquele que tenta esclarecer a impossibilidade de se provar que a justiça está na natureza das coisas ${ }^{3}$; assim, sua relação com a utilidade é fato-valorativa. Se levarmos em conta a forma de se analisar conceitos morais, o discurso em torno de temas éticos precisa ser aberto ao relacionamento estreito entre fatos (utilidade) e valores (justiça) para se fazer valer. Sendo autorizado dizer que teorias éticas engendrem "hipóteses contingentes e fatos genéricos", teorias políticas (ao menos as liberais) parecem necessitar de conceitos fato-valorativos, como os princípios de igualdade e liberdade. Do contrário, Mill teria se mantido fiel às diretrizes do positivismo lógico, algo que não aconteceu. Rawls, por sua vez, acertadamente pensa que seus juízos morais ponderados do equilíbrio reflexivo são fornecidos justamente dessa maneira, ponderando elementos contingentes e fatos genéricos em torno da natureza dos conceitos políticos. Em virtude disso, ele também não trata de "provas" da sua concepção de justiça. Na nossa interpretação, trata-se de uma lição aprendida com os erros e acertos do utilitarista londrino. O fato de uma concepção de justiça ser suscetível de críticas não é o bastante para deixá-la de lado. Na mesma esteira, elementos teóricos persuasivos e até desejáveis, como Mill esperava serem os seus, não são suficientes para ratificar integralmente uma concepção de justiça, nos moldes de Rawls (2002, p.135). Justamente em virtude disso, os juízos morais ponderados ganham importância, apoiados em valores provenientes do senso de justiça:

Juízos ponderados são simplesmente os que são feitos sob condições favoráveis ao exercício do senso de justiça, e portanto em circunstâncias em que não ocorrem as desculpas e explicações mais comuns para se cometer um erro. Presume-se então que a pessoa que emite o juízo tem a habilidade, a

\footnotetext{
a justiça distributiva. Sidgwick acreditava que se trata de algo que precisa ser ratificado do ponto de vista político, tendo em vista critérios intuitivos de justiça. Nesse sentido, ele buscou enfrentar um problema interno a teoria do valor de Mill: a aparente incongruência entre um hedonismo psicológico (lei da universidade da busca pelo prazer) e outro ético (o sacrifício individual tendo em vista a felicidade geral). No primeiro caso temos uma teleologia e, no segundo, a tentativa de justificar uma máxima com base no dever. "Não pude encontrar oposição real entre Intuicionismo e Utilitarismo... O utilitarismo de Mill e Bentham pareceu-me querer uma base: essa base deveria ser apenas suprida por uma intuição fundamental; por outro lado, o melhor exame que eu poderia fazer da Moralidade do Senso Comum não me mostrava princípios claros e auto-evidentes exceto aqueles que foram perfeitamente consistentes com o utilitarismo". Essa característica se dá em um sentido bastante especial: deliberadamente, Sidgwick levou a ideia de justiça para o âmbito da utilidade de modo a ofuscar uma concepção teleológica mais rígida, mas se manteve um baluarte do utilitarismo clássico.

“[...] it must be evident that if compensation in the form of material commodities can be justly given for an encroachment on Freedom, the realisation (sic) of Freedom cannot be the one ultimate end of distributive Justice" (1962, p.278).

"I could find no real opposition between Intuitionism and Utilitarianism. The Utilitarianism of Mill and Bentham seemed to me to want a basis: that basis could only be supplied by a fundamental intuition; on the other hand the best examination I could make of the Morality of Common Sense showed me no clear and self-evident principles except such as were perfectly consistent with Utilitarianism" (1962, p.xxi).

3 CW X: 240.
} 
oportunidade e o desejo de chegar a uma decisão correta (ou que, no mínimo, não deseja evitá-la) (RAWLS, 2002, p.51).

Esse ponto é especialmente interessante, pois admite um nível de intuicionismo muito semelhante àquele que vínhamos reclamando para Mill. A aparente vantagem da teoria da justiça oferecida por Rawls é o limite de ação da intuição, restrita à posição original com suas várias considerações de justiça. Ele admite tal apelo à intuição na "base da teoria da justiça”", mas observa: "tudo somado pode ficar perfeitamente claro onde reside o equilíbrio lógico" (RAWLS, 2002, p.135). A base à qual ele se refere é a posição original, e sua importância dentro da teoria não pode ser facilmente deflacionada, levando em conta sua latente característica intuicionista. Rawls sustenta que as pessoas que escolhem, em um cenário hipotético envolvendo a posição original, podem facilmente optar por uma teoria da justiça com relação às outras, independente da prova: “a demonstração a seu favor não é, estritamente falando, uma prova, pelo menos não por enquanto; mas, nas palavras de Mill, pode representar motivos capazes de persuadir a mente" (2002, p.135).

É preciso observar, seja como for, o entendimento de Rawls sobre o que é o intuicionismo: uma doutrina ligada a um conjunto de princípios que não pode ser reduzido. A esse respeito, o utilitarismo de Mill e a teoria da justiça se distinguem diametralmente quanto aos seus métodos, porque o primeiro lida com o princípio da utilidade - encaixa-se na definição, portanto -, enquanto Rawls tem, na posição original, a escolha dos princípios da justiça. A partir disso, segue-se um construtivismo político, diferente de uma teoria intuicionista tradicional ${ }^{4}$. Segundo Rawls, "uma vez atingido certo nível de generalidade, o intuicionista afirma que não existem critérios construtivos de ordem superior para determinar a importância adequada de princípios concorrentes da justiça” (2002, p.37). Ele é, então, bastante astuto para escapar da sua própria definição de intuicionismo, a partir do estabelecimento de princípios políticos, mas não vê problemas em admitir a intuição como um elemento metodológico importante para sua posição original. Contudo, para Rawls, não podemos enquadrar Mill tão facilmente nessa definição: sua teoria não tem uma pluralidade de princípios básicos que podem chocar-se entre si, mas apenas o princípio da utilidade; não se faz necessário, portanto, um método para comparar princípios.

O ponto central é que a comparação de princípios não é necessária para Mill, se levarmos em conta: i) fatos e valores são conjugados dentro de uma teoria moral tendo como resultado princípios e regras e ii) que se trata de uma teoria declaradamente consequencialista, não sendo necessário um aparato construtivista. Essas duas características parecem autorizar a manobra de Mill no último capítulo do Utilitarianism: conectar o princípio da utilidade com os valores provenientes da ideia de justiça, sem apelar para a natureza desse sentimento.

É importante entender essas duas dificuldades da forma como elas se apresentam no texto de Rawls, começando pela segunda. Assim como ele não foi intransigente com uma concepção de intuição, aceitável na base de seu projeto construtivista, a ideia de que as consequências podem oferecer algum grau de prioridade em meio às concepções de justiça também pode ser sustentada. Trata-se da necessidade de elementos

\footnotetext{
4 É importante ressaltar o exato ponto a partir do qual Rawls admite seu construtivismo: "as concepções de sociedade e pessoa enquanto idéias da razão não são, evidentemente, construídas, assim como tampouco os princípios da razão prática o são. Mas podemos concebê-las como idéias agrupadas e conectadas. [...] Assim, a idéia básica de sociedade é a daquela cujos membros se envolvem não simplesmente em atividades originadas dos comandos de uma autoridade central, mas sim em atividades guiadas por normas e procedimentos publicamente reconhecidos, os quais os membros cooperados aceitam e consideram como fatores que regulam apropriadamente sua conduta" (2000, p.154). 0 construtivismo político se refere à construção de princípios, apenas, a partir da posição original. As concepções normativas de pessoa e sociedade - e o papel público dos princípios de justiça, portanto - têm herança na razão prática kantiana.
} 
que agreguem características socialmente úteis, tendo em vista que o mero consenso em torno das concepções de justiça não é a única coisa de que uma comunidade humana politicamente viável precisa para ter características como "coordenação, eficiência e estabilidade" (RAWLS, 2002, p.6), apresentadas justamente nessa ordem ${ }^{5}$. Acreditamos que essa característica abre espaço para um tipo de consequencialismo por via institucional em Rawls, mas não suficiente para a adjudicação em todos os casos que o liberalismo exige, tendo em vista o indivíduo como um ser em progresso, estabelecendo publicamente regras imperativas de justiça.

Contudo, é preciso observar que um consequencialismo com um viés estritamente constitucional não é capaz de solucionar um problema de justiça externo à teoria da justiça. A ideia de que podemos ter um efeito profilático em sentenças criminais, administrativas, por exemplo, com o consequencialismo limitado a um ambiente puramente institucional (coordenação, eficiência e estabilidade) parece destoar de um raciocínio jurídico que procura evitar danos aos indivíduos em todos os casos. Em boa parte, essa impressão parece residir no fato de que de que uma decisão baseada nas consequências envolvendo uma sentença no âmbito criminal não parece ser puramente institucional: envolve a intenção de indivíduos que decidem por provocar ou não danos aos outros, e mais: não apenas os agentes que estão sendo julgados, mas também aqueles que julgam e proferem determinada sentença. Ainda se encontra dentro desse contexto de julgamento, o fato de que as decisões judiciais buscam um efeito pedagógico através do medo, com a intensão de evitar novos crimes.

O consequencialismo de Rawls, pensado para instituições, tem um critério corretivo no âmbito da justiça e busca aperfeiçoamento tendo em vista sua finalidade maior: promover a justiça social. Rawls parecia estar muito filiado a essa ideia quando escreveu: "o ponto que se deve ter em mente é que a concepção de justiça para a estrutura básica tem valor intrínseco. Não deveria ser descartada só porque seus princípios não são satisfatórios em todos os casos" (2002, p.10). Ele considera, portanto, em primeiríssimo lugar, uma ideia de justiça que fornece um critério por meio do qual se avalia elementos distributivos da estrutura básica da sociedade. A insuficiência da leitura meramente institucional exige um aspecto intuicionista para o estabelecimento dos juízos morais ponderados e Rawls sabia dessa necessidade.

O trabalho de Mill foi diferente nesse aspecto e, por isso, ofereceu avanços no tocante aos desejos inerentes a uma concepção jurídica envolta em problemas de ordem prática que não podem ser resolvidos

\footnotetext{
${ }^{5}$ É preciso que os interesses daqueles que participam de uma comunidade política sejam executados de maneira a se encaixarem em fins sociais coerentes com o consenso em torno das concepções de justiça que foram assumidas (coordenação). Os planos individuais devem ter como ajuste certas finalidades sociais coerentes com a justiça (eficiência). Rawls quer garantir que um esquema de cooperação social deva ser estável, e faz isso por um motivo diferente daquele levantado por Mill que ainda precisava de certas garantias a respeito da estabilidade da democracia (como discutimos no nosso segundo capítulo). É preciso observar que Rawls trata do panorama institucional de uma maneira bastante ampla, pela importância que as instituições, promotoras da justiça, ocupam dentro da sua teoria. Estabilidade, em Rawls, se refere às instituições que devem dar certo rumo às ações daqueles que cooperam, tendo em vista suas regras básicas: "quando ocorrem infrações, devem existir forças estabilizadoras que impeçam maiores violações e tendam a restaurar a organização social" (2002, p.7). Com isso, Rawls chama atenção indiretamente para aquilo que realmente interessa do ponto de vista consequencialista: a observação de que não se deve apenas levar em conta um critério como o distributivo de justiça, mesmo admitindo a importância do seu papel. As concepções de justiça devem especificar direitos básicos, contudo, a maneira como isso é feito pode afetar seriamente problemas ligados à coordenação, eficiência e estabilidade. São questões de ordem consequencialista e Rawls espera que possamos levar em conta essas avaliações. Isso, para ele, é indiferente do fato de que existe certa prioridade na justiça, considerada a virtude mais importante das instituições: "em condições iguais, uma concepção de justiça é preferível a outra quando suas consequências mais amplas são mais desejáveis” (2002, p.7). Ele se refere a consequências mais desejáveis no sentido institucional: coordenação, eficiência e estabilidade. Garante-se, assim, espaço para um tipo de consequencialismo em Rawls.
} 
pelo construtivismo político, especialmente porque esse não é o papel de uma teoria com as características da justiça como equidade. Quando dizemos isso, por certo, precisamos levar em conta que não estamos criando um problema para Rawls, pois, seu objetivo de se afastar das chamadas teorias morais abrangentes ${ }^{6}$ não parece incluir um afastamento da influência delas em vários aspectos da vida social e, inclusive, jurídica dos indivíduos.

Um consequencialismo baseado em princípios factuais e valiosos pode enfrentar certos problemas jurídicos justamente porque o fato da utilidade busca consonância com os valores do senso de justiça. A alternativa a isso seria princípios de ordem religiosa ou estabelecidos com base na ideia de valor intrínseco. A estrutura básica de sociedade onde a justiça ocupa um espaço com valor intrínseco, a qual Rawls se refere, não é a base de sua teoria da justiça como equidade, mas o resultado de princípios já estabelecidos, através do construtivismo político. Por outro lado, estando fatos e valores conjugados dentro de uma teoria moral como a de Mill, temos a vantagem de dispensar a necessidade de um construtivismo e a desvantagem de figurarmos no rol daquilo que Rawls batizou de "teorias morais abrangentes": o princípio da utilidade sustenta, afinal, um imperativo moral. Isso nos leva ao nosso primeiro ponto: a tese de fatos e valores conjugados dentro da mesma teoria moral. Não é possível que possamos levar o consequencialismo e o respeito ao individualismo em consideração simultaneamente sem que tenhamos um arranjo desse tipo, interno ao utilitarismo.

A posição que estamos ressaltando aqui, de que há princípios, inclusive de justiça, naturalmente valiosos na teoria utilitarista liberal, tal qual Mill a prescreveu, já pode ser encontrada em muitos interpretes clássicos, mesmo que o tenham feito indiretamente, como John Fitzpatrick, quando distinguia o minimalismo de Mill de um utilitarismo de regras:

O utilitarismo de regras afirma que regras morais são justificadas se todos que as seguem têm a melhor consequência. O utilitarismo minimalista [de Mill] rejeita isso e considera os custos da implementação e aplicação de regras morais como práticas sociais gerais. Sob o utilitarismo minimalista, atos são moralmente incorretos apenas quando violam "uma regra moral que vale o custo de ser instituída e aplicada como prática social geral". Desta forma, muitos atos desejáveis não são moralmente obrigatórios?.

A regra moral violada em um crime culposo, por exemplo, vale o custo de ser instituída como prática social geral. Ela está amparada por um princípio valioso do ponto de vista político, tendo em conta inclusive a justificação pública de uma sentença. Isso torna os atos que violam tais regras censuráveis. Por isso, nosso sentimento de justiça reclama punições em muitos cenários envolvendo apenas a culpa do agente moral e não sua intenção de causar dano. Muitos desses mesmos atos não seriam moralmente obrigatórios em muitos casos onde seriam apenas desejáveis. "De fato, poucos atos desejáveis podem satisfazer os padrões da obrigação moral”, completa Fitzpatrick, na mesma citação. Ou seja, o liberalismo precisa conviver com muitos atos desejáveis que não podem ser instituídos como regras, levando em conta o fato que que não é possível arcar com os custos sociais de sua implementação, do ponto de vista do subjugo das liberdades individuais,

\footnotetext{
${ }^{6}$ Há aqui muita resistência na ideia de que a utilidade total ou mesmo a utilidade média (versão que ele atribui a Mill) possam conduzir aos dois princípios da justiça. Rawls testa ambas as alternativas e argumenta que elas não podem dar prioridade ao princípio da liberdade frente ao princípio da diferença (2002, p.173s).

7 "Rules-utilitarianism affirms that moral rules are justified if everyone's following them would have the best consequences. The minimalist utilitarian rejects this and considers the cost of implementing and enforcing moral rules as general social practices. Under minimalist utilitarianism, acts are morally wrong only when they violate 'a moral rule that is worth the cost of being instituted and enforced as a general social practice'. Thus, many desirable acts are not morally obligatory. In fact few desirable acts would meet the standards of moral obligation" (1988, p.85).
} 
para citar o exemplo mais conhecido.

Tratando-se de "regras morais como práticas sociais gerais", como faríamos para acolhê-las sem levar em conta o peso e a representatividade que princípios encontram nas nossas comunidades morais? Para isso, Rawls criou uma pretensa solução externa ao utilitarismo, mas que ainda assim sustenta um conceito de liberdade tal qual o de Mill: compreendendo a distinção entre fatos e valores, e aproximando essa diferença em um sistema. Tratando-se de um constitucionalista, ele observou uma liberdade política (ou institucional) e o valor da liberdade, ligado à capacidade da pessoa. A liberdade institucional, garantida pelo princípio político da liberdade igual, está ligada às liberdades políticas. Por outro lado, o valor da liberdade diz respeito à capacidade que indivíduos ou grupos têm para promover seus objetivos de vida dentro da estrutura definida pelo sistema político. A noção de liberdade política, portanto, faz parte do senso de justiça de todos; contudo, o valor da liberdade para cada um precisa ser analisado tendo em vista os diferentes meios para se alcançar os fins. Essa distinção encontra-se na definição que Rawls dá para o princípio de liberdade, da teoria da justiça (2002, p.221).

Mill tem como ponto de partida o valor da liberdade de acordo com os desejos de cada um, mas não parece negar, com isso, o valor da liberdade do ponto de vista social, por exemplo, com a implementação das regras que valem a pena serem socialmente ratificadas. O valor da liberdade, não sendo o mesmo para todos, com distinções de autoridade e perfil financeiro, não deve ser confundido com uma liberdade institucional desigual.

Rawls aceita com tranquilidade mecanismos compensatórios, levando em conta a justiça social, resultado da posição original. Essa distinção é uma forma de valorar um conceito político que corre o risco de ser puramente negativo, e ele sabia que esse poderia ser um problema para o seu princípio da justiça mais fundamental, de liberdade igual. A distinção entre liberdade positiva e negativa, para ele, não serve como definidor do conceito de liberdade, mas como atestado de que os valores relativos das várias liberdades conflitam entre si (RAWLS, 2002, p.218). Sua estratégia, assim, sempre será discutir o valor da liberdade em conexão com limitações legais e constitucionais.

É importante observar que Rawls, pela força da normatividade institucional exigida pela sua teoria, interpreta o conceito de liberdade do utilitarismo de Mill pelo viés de fundamentar instituições livres ${ }^{8}$ e não parece discordar nem do resultado nem da fundamentação. Se, para o primeiro, trata-se da promoção da justiça social por meio da justiça como virtude das instituições; no segundo, trata-se de promoção institucional da liberdade para estimular virtudes fortes e vigorosas no indivíduo. O critério de valor estabelecido por Mill é baseado na escolha do agente moral, e os diferentes valores do princípio têm como parâmetro os interesses do homem como um ser que progride. O último desses aspectos Rawls interpreta positivamente; já o primeiro - o peso do critério de escolha para a valoração - é visto com mais desconfiança, na medida em que se afasta de algo ligado à sua noção de justiça social. Por outro lado, do ponto de vista valorativo, Mill se preocupa com instituições que possam maximizar o valor da liberdade; a tradição contratualista, na interpretação de Rawls, não pode ter nas liberdades uma ferramenta de aumentar a soma dos valores intrínsecos ou o maior saldo líquido de satisfação (2002, p.227).

A justificação da liberdade em um ambiente utilitarista é muito bem interpretada por Rawls. Ele

\footnotetext{
8 Curiosamente Rawls observa isso no capítulo III de On Liberty (Of Individuality, as One of the Elements of Well-Being) e não, como era de se esperar, no capítulo II (Of the Liberty of Thought and Discussion). Contudo, a respeito da irrestrita liberdade de pensamento e discussão - para Rawls "liberdade de consciência" -, o autor americano entende a importância do tema para exemplificar o modo como a justiça como equidade pode ratificar os argumentos em torno do princípio da liberdade igual (2002, p.676, nota 8 e p.227).
} 
compreende o valor das instituições livres descrito por Mill, mas não parece aceitar uma justificativa com base na preferência dos indivíduos de viver com base em instituições livres apenas pelo critério de desejos mais qualificados. Contudo, trata-se de uma conexão muito estreita entre o ambiente liberal e o utilitarismo. A marca indelével dessa característica que une moralidade e o desejo de viver em instituições livres pode ser facilmente identificada logo no início de Representative Government. Essa posição de Mill não leva em conta apenas as características dos valores inerentes à democracia, mas diz respeito ao sustentáculo de qualquer instituição política. São três as condições: i) consentimento do povo ou ao menos a não recusa integral de uma determinada forma de governo; ii) liberdade de se manifestar em torno da legitimidade da instituição; iii) vontade e capacidade de fazer aquilo que a forma de governo exige do povo (CW XIX:376). Quando a sociedade ratifica as instituições como sendo livres, tendo em vista essas condições, o faz por motivos contingentes e históricos, tendo como horizonte o desejo de progredirem em conjunto com características plurais.

Indivíduos vivendo sob a proteção de instituições livres não têm a tendência de recuar em sua escolha por tal modelo. Se formos perguntados sobre os motivos de esses homens não desejarem a subserviência e a tirania, nos encaminhamos para uma resposta utilitarista e, portanto, moral que não pode ser desvinculada do simples desejo dos homens de não retrocederem a um período "sem história":

O princípio progressista, seja qual for sua forma (amor da liberdade ou melhoramento), contudo, é antagonista à influência do Costume, envolve ao menos a emancipação desse cabresto: e a disputa entre os dois constitui o interesse superior da história da humanidade. A maior parte do mundo, propriamente falando, não tem história, porque o despotismo do Costume está completo?.

A formação de instituições emancipadas leva em conta vontades e interesses: forças sociais ativas por meio da opinião pública. Mill considerava os seres humanos em permanente progresso e não sobrevalorou interesses econômicos diante da força dos desejos propagados por concepções mais esclarecidas do ambiente institucional, quando exemplificou este quadro:

Não foi por nenhuma mudança na distribuição de interesses materiais, mas por ampliação das convicções morais que a escravidão negra vem sendo encerrada no Império Britânico e outros lugares. Os servos na Rússia devem sua emancipação, se não a um sentimento de dever, ao menos ao crescimento de uma opinião mais iluminada sobre o verdadeiro interesse do Estado. É o que os homens pensam que determina como eles agem ${ }^{10}$.

Comparando teoria política (On Liberty) com prática política (Representative Government), deparamonos com uma resposta apoiada no princípio da utilidade e ligada a uma justificativa por meio dos desejos daqueles que deliberam publicamente. Por certo, ele não parece esperar que os critérios para compor um conjunto de políticas públicas institucional estejam à disposição de qualquer povo a qualquer momento histórico. Nesse sentido, não parece haver incompatibilidade na resposta utilitarista se levarmos em conta o

9 "The progressive principle, however, in either shape, whether as the love of liberty or of improvement, is antagonistic to the sway of Custom, involving at least emancipation from that yoke: and: the contest between the two constitutes the chief interest of the history of mankind. The greater part of the world has, properly speaking, no history, because the despotism of Custom is complete" (CW XVIII:272).

10 "It was not by any change in the distribution of material interests, but by the spread of moral convictions, that negro slavery has been put an end to in the British Empire and elsewhere. The serfs in Russia owe their emancipation, if not to a sentiment of duty, at least to the growth of a more enlightened opinion respecting the true interest of the State. It is what men think, that determines how they act" (CW XIX:382). 
liberalismo, tendo como ponto de partida uma teoria do valor individualista, inserido em comunidades plurais. As condições para a manutenção de formas de governos e instituições precisam ser vistas a partir desses parâmetros. Essa mesma justificativa moral não deixa de ser política quando observamos uma posição afastada de um senso naturalizado de justiça. A relação estabelecida entre fatos e valores dentro do princípio da liberdade, indispensável para a compreensão de qualquer teoria do valor contemporânea, ofereceu alternativa à mesma questão, sem abdicar do pano de fundo do liberalismo político.

Rawls optará por uma via contratualista, porque seu objetivo é a formação de instituições democráticas como base da sociedade e não meramente como resultado de um processo histórico que fez com que os homens escolhessem a liberdade igual.

Sem pressupostos desse tipo, Rawls interpreta que corremos sempre o risco de assistir à sujeição da liberdade igual. Mesmo assim, ele vê em On Liberty três fundamentos da garantia das instituições livres: i) a necessidade de se desenvolver as capacidades dos homens para atividades valiosas; ii) a racionalidade e o esclarecimento dependem da liberdade das instituições, suas preferências bem fundamentadas não podem "caminhar às cegas"; iii) os seres humanos preferem viver em instituições livres.

A respeito do último fundamento das instituições livres, Rawls ainda acrescenta: "pelo critério de escolha de Mill, as instituições livres têm valor em si mesmas como aspectos básicos de formas de vida preferidas racionalmente" (RAWLS, 2002, p.228). Isso mostra a filiação de Rawls ao liberalismo de Mill e deixa claro que não há incompatibilidade em administrar fatos e valores dentro do mesmo corpo teórico quando se trata dos critérios para a estabilidade das instituições ${ }^{11}$.

Esses três fundamentos são levados em conta por Rawls em virtude do seu interesse pela liberdade do ponto de vista institucional, como mostramos. A observação do contratualista americano nos oferece ensinamentos importantes no tocante à compreensão do princípio da liberdade em Mill como um fato institucional valioso das sociedades ocidentais e plurais como as conhecemos. Apesar de uma plataforma liberal muito bem conectada entre ambos, a resistência de Rawls ao utilitarismo, no entanto, se manteve inabalada. Ele não vê como escapar de uma justificação envolvendo uma variante de uma concepção de bem, quando vamos dar valor ao fato político da liberdade igual:

Deve-se supor uma certa semelhança entre os indivíduos, por exemplo, a sua capacidade de desenvolver atividades e interesses humanos na qualidade de seres capazes de progresso, e além disso o princípio do valor marginal decrescente dos diretos básicos, quando atribuídos aos indivíduos. $\mathrm{Na}$ falta desses pressupostos, a promoção dos objetivos humanos sempre pode ser compatível com a opressão ou, pelo menos, com a severa restrição da liberdade de alguém (RAWLS, 2002, p.228s).

Quando Rawls exige do utilitarismo uma semelhança dos indivíduos tendo em vista o progresso e uma filiação ao valor marginal decrescente, para garantia de direitos individuais, ele mantém aberto espaço

\footnotetext{
${ }^{11}$ Além disso, outro ponto de encontro é que o construtivismo político proposto pelo americano diz respeito tanto aos fatos presentes na estrutura quanto ao valor do conteúdo político do liberalismo. Rawls distingue seu construtivismo político do construtivismo moral kantiano e do intuicionismo na terceira conferência do Liberalismo Político (2000, p.134ss). Contudo, é preciso fazer notar que ele adota um procedimento que é intuicionista, ao menos em alguma medida, uma vez que os juízos presentes na cultura política da sociedade são também intuições. A baronesa Onora O'Neill observa os motivos: "grande parte do esforço feito por Rawls na complexa construção da justiça é necessária para salvar sua ideia intuitiva de justiça como equidade, que é posta em perigo por sua - talvez idealizada - assunção de que o raciocínio humano é governado pelo interesse pessoal, cujo justo por trás de um véu de ignorância pode ser justificado com referência às normas concretas corporificadas nos 'juízos ponderados' de uma sociedade democrática liberal. 0 dispositivo de posição original como um todo é intuído para frustrar os resultados desastrosos do egoísmo racional que foi imputado" (2006, p.63s).
} 
para um conteúdo socialmente valorado, que não é construído na base do princípio da utilidade, mas, apenas, na sua relação com a justiça. A preocupação de Rawls é com a garantia do funcionamento dos princípios de liberdade e igualdade integralmente para todos, sem espaço para violação de direitos individuais frente ao coletivo; e os fundamentos das instituições livres oferecidos por Mill são, de fato, insuficientes para isso. É preciso que possamos levar em conta os princípios políticos como emancipados, factíveis e valiosos, ou que, ao menos, não seja estabelecido um impedimento para isso.

\section{Considerações Finais}

A liberdade institucional é o real substrato fato-valorativo da teoria política de Mill e a fundação do liberalismo contemporâneo não está na liberdade negativa, sem uma teoria do valor, ou na integral autonomia do sujeito racional. A teoria utilitarista que busca "evitar danos" tenta, em primeiro lugar, incorporar uma justificação política que limite o Estado, ao menos, na reivindicação mais elementar da contemporaneidade: evitar a tirania, a intolerância institucionalizada etc; ainda, oferecer um manual jurídico flexível para evitar injustiças. Foi ao natural que Rawls compreendeu o cerne desse projeto graças à estreita conexão entre a ideia de tolerância, fundada com o liberalismo ${ }^{12}$, e sua concepção de pluralismo razoável, ambas interdependentes.

As sociedades bem ordenadas dependem da diversidade do pluralismo, mas também, segundo o próprio Rawls, de um entendimento comum de que uma doutrina moral abrangente só poderia se manter no poder com coerção estatal. Em terceiro lugar, elas precisam de um regime democrático perene, apoiado voluntariamente por uma maioria considerável dos concidadãos (RAWLS, 2000, 80s). O utilitarismo, assim como uma deontologia Kantiana, esbarra no segundo desses fatos gerais em torno de regimes políticos liberais. Contudo, o utilitarismo de Mill especificamente, mesmo não sendo a inspiração construtivista de Rawls, autoriza níveis muito semelhantes de intuicionismo, justamente para garantir a liberdade institucional. A diferença entre o institucionalismo dos dois liberais, no sentido que apresentamos, é que Mill comprometeu fatos (utilitarismo) e valores (justiça) como as prescrições de fundação do próprio modelo teórico liberal; enquanto Rawls tem outro alicerce factual, justamente o fato do pluralismo razoável (pressuposição de sociedades liberais) e a concepção básica de justiça como equidade, valorativa do ponto de vista intuicionista. Assim sendo, é de se esperar que esteja em Mill a exigência de um estado menos abrangente para maximizar a justiça social. Parece pouco factível que uma concepção de estado com essas características possa se dedicar a manter o status de uma teoria moral abrangente por meio da coerção. De qualquer forma, a acusação de Rawls de que seria necessário um estado opressor para fazer valer uma doutrina moral abrangente não é dirigida propriamente a Mill, mas ao utilitarismo como um todo.

\footnotetext{
12 A tese de que o liberalismo é, fundamentalmente, uma posição política com uma exigência interna por tolerância pode ser observada no artigo de Judith Shklar. Em resumo, é a ideia de que o liberalismo contemporâneo não tem como ponto de partida teorias que dão à autoridade estatal o direito incondicional de impor crenças, de forma hostil à liberdade pessoal (Hobbes). 0 ponto que marca a fundação do liberalismo é caracterizado pela noção de que só é possível desenvolvimento do conhecimento e da moralidade em sociedades livres onde instituições de aprendizagem podem substituir políticos e governos, tendo esses últimos um papel institucional menos central. Shklar atribui essa "fundação do liberalismo", no sentido, contemporâneo da expressão, respectivamente, a Locke e Mill (1989, p.27).
} 


\section{Referências}

MILL, John Stuart. Utilitarianism / Three Essays on Religion et al. In Collected Works, v.10. Toronto: Toronto University Press; ROBSON, John (Ed.), 1969.

. On Liberty. In Collected Works, v.18. Toronto University Press; ROBSON, John (Ed.), 1977.

. Considerations On Representative Government. In Collected Works, v.19. Toronto: Toronto University Press; ROBSON, John (Ed.), 1977.

BENTHAM, Jeremy. Uma Introdução aos Princípios da Moral e da Legislação. Tradução: Luiz João Baraúna. Coleção Pensadores, v.34. São Paulo: Abril Cultural, 1974.

BERLIN, Isaiah. Introdução. In MILL, John Stuart. A Liberdade; Utilitarismo. Tradução: Eurice Ostrensky. São Paulo: Martins Fontes, 2000, pp. VII-LIV.

MOORE, G. E. Principia Ethica. Tradução: Maria M. R. Santos e Isabel P. dos Santos. Lisboa: Fundação Calouste Gulbenkian, 1999.

O'NEILL, Onora. Autonomy, individuality and consent. Autonomy and Trust in Bioethics. Cambridge: Cambridge University Press, 2002, pp.29-48.

. Em Direção à Justiça e à Virtude: uma exposição construtiva do raciocínio prático. Tradução: Leila Mendes. São Leopoldo: Unisinos, 2006.

PUTNAM, Hilary. The Collapse of The Fact/Value Dichotomy. Harvard University Press. London, 2002. pp.127-149.

Fact and Value. Reason, Truth and History. Cambridge University Press: Cambridge, 1998,

RAWLS, John. História da Filosofia Moral. São Paulo: Martins Fontes, 2005.

Uma Teoria da Justiça. Tradução: Almiro Pisetta; Lenita M. R. Esteves. 2. ed. São Paulo: Martins Fontes, 2002.

. Liberalismo Político. Tradução: Dinah de Abreu Azevedo. São Paulo: Ática, 2000.

SHKLAR, Judith N. The Liberalism of Fear. In ROSENBLUM, Nancy L (org). Liberalism and the Moral Live. Cambridge: Harvard University Press, 1989, pp.21-38.

SIDGWICK, Henry. The Methods of Ethics. London: Palgrave Macmillan, 1962.

Artigo recebido em: 24 de março de 2020

Artigo aceito em: 04 de maio de 2020 